\title{
Fracture Toughness and Tribological Properties of Cemented Carbides Machined by Sinking Electrical Discharge Machining
}

\author{
Timm Petersen, Ugur Küpper, Tim Herrig, Andreas Klink and Thomas Bergs
}

Timm Petersen. Laboratory for Machine Tools and Production Engineering (WZL) of RWTH Aachen University, Campus-

Boulevard 30, 52074 Aachen, Germany

Corresponding author: Timm Petersen.E-mail address: t.petersen@wzl.rwth-aachen.de

Ugur Küpper. Laboratory for Machine Tools and Production Engineering (WZL) of RWTH Aachen University, Campus-Boulevard 30, 52074 Aachen, Germany

Fraunhofer Institute for Production Technology IPT, Steinbachstraße 17, 52074 Aachen, Germany

Tim Herrig. Laboratory for Machine Tools and Production Engineering (WZL) of RWTH Aachen University, Campus-Boulevard 30, 52074 Aachen, Germany

Fraunhofer Institute for Production Technology IPT, Steinbachstraße 17, 52074 Aachen, Germany

Andreas Klink. Laboratory for Machine Tools and Production Engineering (WZL) of RWTH Aachen University, Campus-Boulevard 30, 52074 Aachen, Germany

Thomas Bergs. Laboratory for Machine Tools and Production Engineering (WZL) of RWTH Aachen University, Campus-Boulevard 30, 52074 Aachen, Germany

Fraunhofer Institute for Production Technology IPT, Steinbachstraße 17, 52074 Aachen, Germany

Abstract. The quality of a forming process highly depends on the pressure applied to the workpiece. Consequently, the demand for higher workpiece qualities results in a demand for tools that can withstand high compressive stresses. Moreover, the tendency of using materials like high-strength steels as workpiece material, urges the need for tool materials that can withstand high compressive stresses and are resistant to wear. A class of materials that offer a combination of hardness or wear resistance and ductility are cemented carbides. However, these properties hamper their machining with conventional cutting technologies. Due to its electro-thermal working principle, Electrical Discharge Machining (EDM) is able to machine materials independently from their mechanical properties. On the other hand, the removal process is accompanied by thermal stresses, which can cause residual stresses and micro cracks near the machined surface. Due to their pre-existing stresses from the sintering process, cemented carbides are especially susceptible for these kind of damages. It is therefore necessary to identify the impact of EDM on the material. Different machining strategies are tested with two different types of cemented carbides and examined regarding their fracture toughness. The crack surfaces resulting from the three point bending test are microscopically inspected regarding failure initiation. Additionally pin-on-disc tests are conducted to determine the influence of the EDM strategies on the tribological properties of the machined cemented carbides.

Keywords. Electrical Discharge Machining, Cemented Carbide, Fracture Toughness

\section{Introduction}

Forming processes become increasingly important in manufacturing due to the superb properties of formed parts and their material utilization [1]. Nevertheless, several trends increase the challenges the forming industry is facing. One trend is the implementation of lightweight design, which utilizes higher-strength workpiece materials that enable parts with thinner wall thicknesses. Furthermore, these trends also aim for net-shape part production, which reduces subsequent machining steps and therefore has to create a variety of different shapes and produce parts with higher accuracy and lower tolerances. Both examples result in higher tool loads that reduce their durability [2, 3]. Since conventional tooling solutions cannot meet these increased demands, new materials have to be applied. A class of materials that is able to withstand these increased compressive stresses and is very resistant to wear is that of cemented carbides [4]. However, conventional machining of cemented carbides is hindered due to the properties that 
Fracture Toughness and Tribological Properties of Cemented Carbides Machined by Sinking...

its use as a tool material benefits from. Depending on the composition of the cemented carbide and the required geometry, machining becomes either very uneconomical because of expensive tools and long machining durations or machining is not possible at all [5]. Electrical Discharge Machining (EDM) can provide a feasible alternative that enables machining of a large variety of geometries and material compositions. Due to its thermo-electrical working principle that melts and evaporates the workpiece material, it can machine materials independently from their mechanical properties [6]. Although, EDM remains to have a bad reputation caused by early investigations on the influence of the EDM process on surface integrity of cemented carbides and the resulting mechanical properties. Since cemented carbides consist of two or more components that have different thermo-physical properties and the EDM process punctually applies heat for short durations, large spatial and temporal thermal gradients occur and can cause tremendous residual stresses. This can result in cracks caused already during machining but also in premature failure of the workpiece during its application [7]. In order to overcome these difficulties and reduce the negative impact EDM can have on the mechanical properties of the workpiece, different post processing strategies like high temperature annealing or polishing can be applied [7, 8]. Another approach is to continue ED-machining with needle type discharges that provide a reduced discharge energy within a shorter discharge duration. Since these findings by Juhr et al. [9] show promising results on the bearable bending fraction stress, but were only applicable for Wire-EDM, Bergs et al. [10] investigated appropriate super-finishing strategies for Sinking-EDM. It was shown that the negative impact on the surface integrity of the cemented carbides can be reduced and therefore the averagely bearable bending stress in the flexural fatigue tests could be increased [10]. In this paper, named findings are broadened through presenting further mechanical and tribological properties of cemented carbides, which were solely machined by EDM.

\section{Experimental Setup}

The tribological properties were tested on a lathe equipped with a shaft as depicted in Figure $1 \mathrm{a}$ ). In this pin-oncylinder setup [11], a pin is forced onto a rotating counterpart. Similar to a pin-on-disk test, the rotation is maintained at a constant speed and the resulting force acting tangentially is measured. The pins consisted of cemented carbide, while there were three pins of each material and surface condition. Additionally, two ground pins of both materials were used as a reference. The shaft consisted of peened steel $42 \mathrm{CrMo} 4$. The traverse rupture strength was determined using five specimens of two different cemented carbide grades and three varying machining strategies. The tests were executed on a Shimadzu universal testing machine by the company Ceratizit. The tests were conducted according to ISO 3327 with a rectangular, type B shape as displayed in Figure $1 \mathrm{~b}$ ). Since the test pieces were machined post sintering, only small chamfers were needed on the long side of the specimens resulting in the correction factor being $\mathrm{k}=1$ [12]. The stress was increased with a speed of $50 \mathrm{MPa} / \mathrm{s}$. 
a)

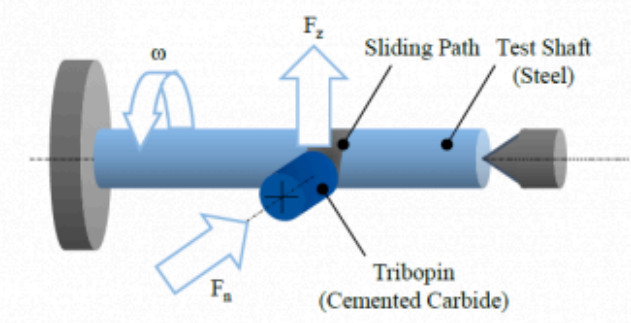

Friction Test a)

\begin{tabular}{|c|c|c|c|c|}
\hline $\begin{array}{c}\mathbf{F}_{\mathbf{n}} / \\
\mathbf{N}\end{array}$ & $\begin{array}{c}\boldsymbol{\omega} / \\
\mathbf{m m} \cdot \mathbf{m i n}^{-1}\end{array}$ & $\begin{array}{c}\mathbf{L} / \\
\mathbf{N} \cdot(\mathbf{m m} \cdot \mathbf{s})^{-2}\end{array}$ & $\begin{array}{c}\mathbf{h} / \\
\mathbf{m m}\end{array}$ & $\begin{array}{c}\mathbf{w} / \\
\mathbf{m m}\end{array}$ \\
\hline \multirow{2}{*}{5000} & 300 & 50 & $\begin{array}{c}5.07 \\
\pm 0.04\end{array}$ & $\begin{array}{c}6.65 \\
\pm 0.1\end{array}$ \\
\hline
\end{tabular}

b)

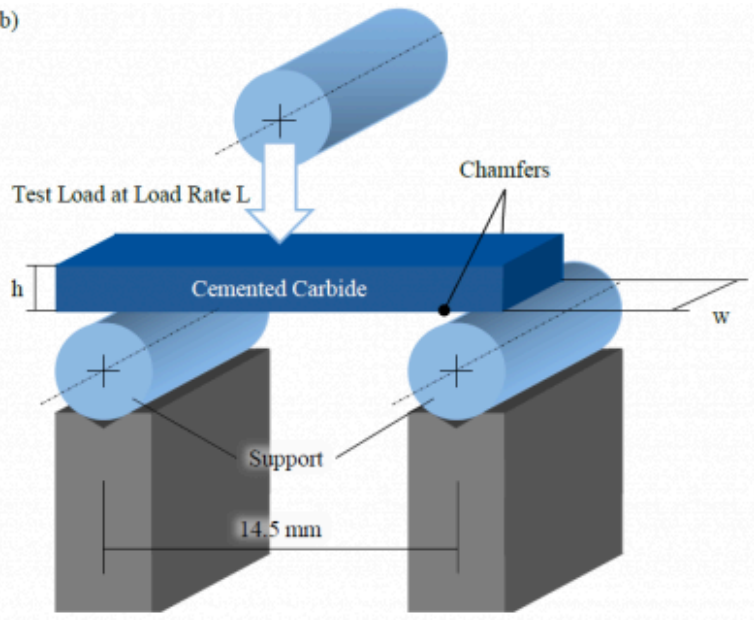

Fig. 1: a) Pin-on-Cylinder test setup for determination of the coefficient of friction and testing parameters; b) 3-point bending test setup for determination of traverse rupture strength and testing parameters.

Two grades of WC-Co cemented carbides, as obtainable at Ceratizit, are examined. Their composition and mechanical properties can be found in Figure 2 a). Primarily, the specimens were cut close to their desired shape through Wire-EDM on a GFMS CUT $2000 \mathrm{X}$ OilTech. The best available machining technology with seven trim cuts and an aimed surface roughness of $\mathrm{Ra}=0.2 \mu \mathrm{m}$ was chosen in order to reduce the impact this preparation step has on the investigation. The remaining offset on the specimens, as depicted in Figure 2 b), was removed with Sinking-EDM on a GFMS FORM 2000 VHP. In both machines, the dielectric Ionoplus IME-MH by oelheld was used. The wire electrode was plain brass with a diameter of $0.2 \mathrm{~mm}$ and the sinking electrodes consisted of copper-tungsten with $80 \mathrm{wt}$.- $\%$ tungsten. The machining parameters and the classification of the different machining strategies are shown in Figure $2 \mathrm{c}$ ). The parameter SBOX is the dominant factor determining the capacitors used in the corresponding machining step and thus determines the discharge energy. However, the parameter is encrypted and the number does not correspond to the actual physical capacity. The parameter P denotes the break in between the discharges and the parameter U displays the open circuit voltage, which shows that the polarity is reversed for all but the last two machining steps to reduce wear. The values given in the coloumn Ra display the arithmetic surface roughness that is expected by the machine tool for the given parameters. The machine tool also displays parameters I and T which only describe a tendency but not the actual values [13]. The discharge duration varied between $3 \mu$ s and $0.1 \mu$ s and the maximum discharge current between 200 A and 3 A. Machining durations, material removal rates and relative wear were measured for all specimens. For some additional specimens that were not considered during the following tests, surface roughness, recast layer, crack length and the depth of the heat affected zone were measured. 
a)

\begin{tabular}{|l|l|l|}
\hline Cemented Carbide Grade & CTF30 & UMG01 \\
\hline Binder / wt- $\%$ & 15 & 0.4 \\
\hline Grain Size / $\boldsymbol{\mu m}$ & $0.8-1.3$ & 0.2 \\
\hline Vickers Hardness / HV10 & 1250 & 2675 \\
\hline Traverse Rupture Strength / MPa & 3100 & 2400 \\
\hline
\end{tabular}

b)

\section{Offset removed by SEDM}

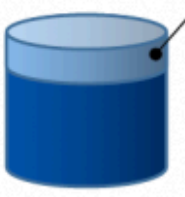

Pin on CylinderSpecimen

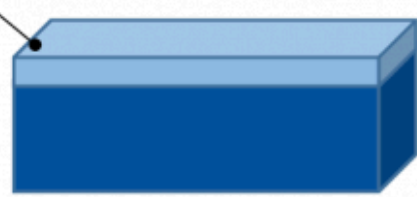

Traverse Rupture StrengthSpecimen c)

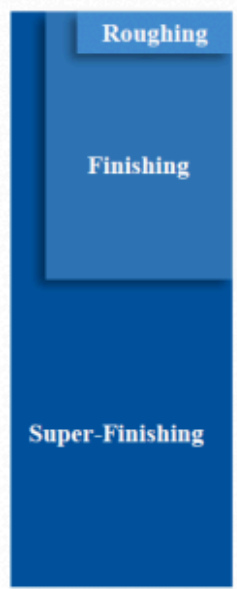

\begin{tabular}{l|l|l|l}
$\mathbf{P} / \mu \mathrm{s}$ & $\mathrm{U} / \mathrm{V}$ & $\mathrm{SBOX}$ & $\mathrm{Ra} / \mu \mathrm{m}$
\end{tabular}

\begin{tabular}{|r|r|r|r|}
\hline 100 & -200 & 350 & 3.16 \\
\hline 50 & -200 & 114 & 2.51 \\
\hline 19.4 & -200 & 82 & 2 \\
\hline 15 & -200 & 74 & 1.58 \\
\hline 15 & -200 & 69 & 1.26 \\
\hline 10 & -200 & 67 & 1 \\
\hline 7 & -200 & 246 & 0.79 \\
\hline 4.5 & -200 & 219 & 0.63 \\
\hline 3.6 & -200 & 199 & 0.5 \\
\hline 3.6 & -200 & 196 & 0.4 \\
\hline 3.6 & -170 & 195 & 0.31 \\
\hline 3.6 & 170 & 195 & 0.25 \\
\hline 3.6 & 120 & 193 & 0.2 \\
\hline
\end{tabular}

Fig. 2: a) Composition and mechanical properties of both cemented carbide grades according to Ceratizit; b) geometry of both types of specimen; c) SEDM parameters and assignment of machining strategies.

\section{Results}

The material removal rate (MRR) of the Sinking-EDM process is presented in Figure 3 a) for both materials and all machining strategies. It can be seen, that the coarser grained material CTF30 is machined almost twice as fast as UMG01 during the roughing operation. The reason for this large difference can most likely be found in the binder content of the two materials. CTF30 has a binder content of approximately $15 \mathrm{wt} .-\%$ and UMG01 is almost free of binder. The binding cobalt has a melting temperature that is well below that of tungsten-carbide. It is possible, that entire WC-grains are ejected because the surrounding binder has been molten and removed [14]. Therefore, less material has to be removed thermally and the process is faster. The difference of MRR between the two materials becomes smaller the more machining steps are conducted. This may be caused by the reduced discharge energy that cannot remove the entire binder material surrounding the WC-grains and therefore all the material has to be removed thermally. Figure $3 \mathrm{~b}$ ) displays the average surface roughness Ra of both materials and all investigated surface conditions. It is revealed that the surface roughness of the finely grained material UMG01 is lower for all surface conditions. Even though the grain size of CTF30 is larger than that of UMG01, the worse surface roughness can not be attributed to this circumstance. As stated by Bergs et al. [10], in the SEM images of the cross sections it was observed, that the grains are completely covered by the molten and resolidified white layer for roughing and finishing. Only for the cross sections of the superfinished workpieces the carbide grains are close enough to the surface, but the difference between the two materials becomes almost negligibly small. Accordingly to the MRR, the actual reason can be found in the compositions of the materials. Since the white layer of CTF30 contains large amount of cobalt, more material can be molten per discharge and the average crater sizes are larger than those of UMG01 that almost does not contain any cobalt. 

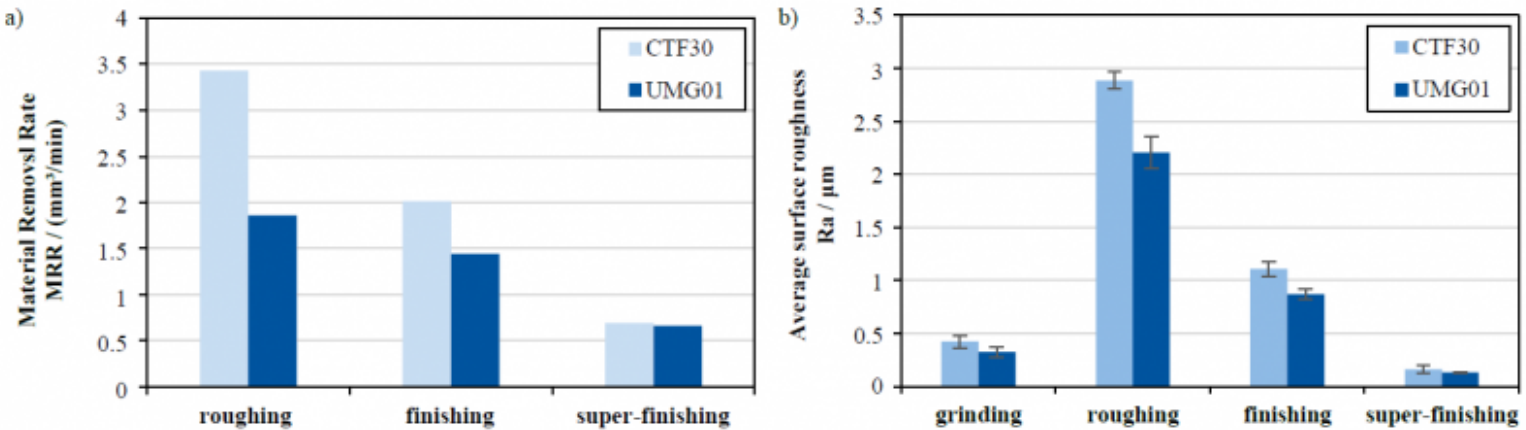

Fig. 3: a) Material removal rate of the Sinking-EDM process for both materials and all three machining strategies; b) average surface roughness of both materials and all investigated surface conditions.

The coefficient of friction (COF), which is depicted in Figure 4 a), was calculated by dividing the resulting tangential force by the force that was applied perpendicular to the surface of the cylinder. It was expected that the COF displays the same tendencies as the surface roughness of the different cemented carbide pins, with a larger friction coefficient for the roughed and finished pins than for the super-finished and the ground pins. On the one hand, it can be seen that the different COFs of CTF30 do not differ largely once the uncertainty of the measurement is taken into account. On the other hand, for finely grained material UMG01, the confidence of the results is larger and the results resemble the graph of the surface roughness. In this investigation, both materials had a COF of less than $\mu=0.2$. Llanes et al. [15] found slightly larger COFs for three machining strategies that resulted in similar surface roughnesses and with a similar pin material to CTF30. Three additional tests with even better resulting surfaces, were giving COFs around $\mu=0.1$. Zhao et al. [16], who were using polished cemented carbide pins with a surface roughness of $\mathrm{Ra}=0.5 \mu \mathrm{m}$ found a COF of $\mu=0.4$. Although, they were testing with a titanium alloy as counterpart and at a significantly higher sliding velocity of $\mathrm{v}=95 \mathrm{~m} / \mathrm{min}$. Fang et al. [17] used a material similar to CTF30, which was laser textured and found a COF slightly lower, in the same range as UMG01, between $\mu=0.1$ and $\mu=0.15$. This is most likely caused by the lubricant that was fed into the contact zone. However, it has to be noted, that the sliding distance employed by Zhao et al. [16] was significantly longer than those in the present tests and those presented by Fang et al. [17]. The present experiments were discontinued shortly after a loud squeaking noise occurred. Because of the geometry of the sliding pair, a linear contact as opposed to the desired point contact was present and most likely caused a stick-slip effect that created the noise. The time until the noise occurred is depicted in Figure $4 \mathrm{~b}$ ) and the corresponding maximum sliding distance is approximately $1.25 \mathrm{~m}$. Only little dependencies between the two graphs can be found in Figure 4 .
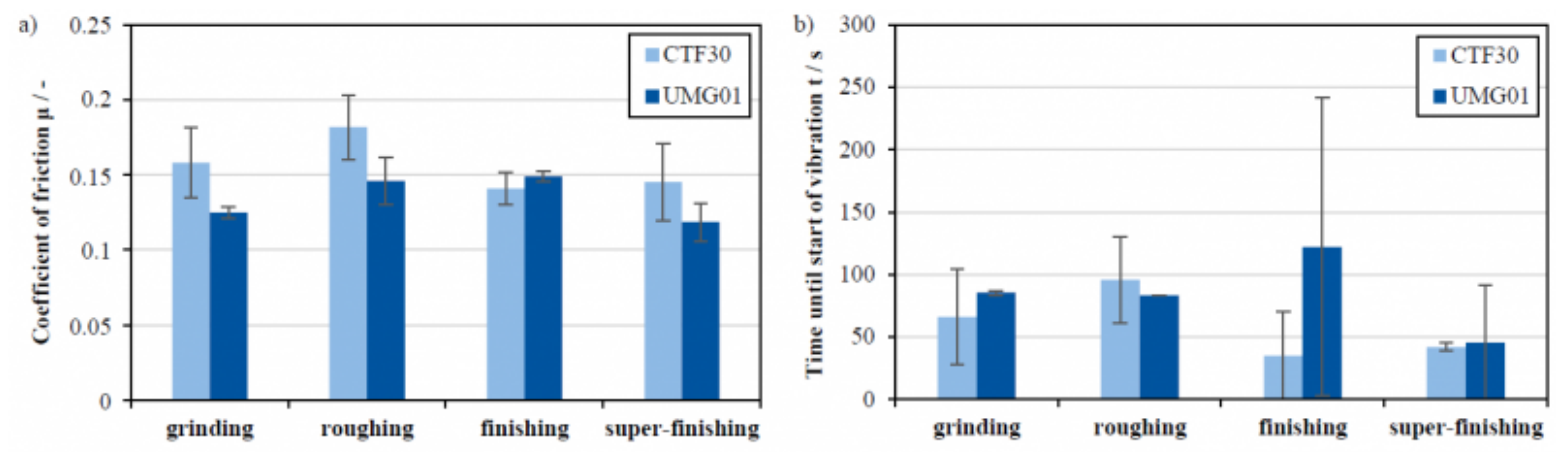
Fracture Toughness and Tribological Properties of Cemented Carbides Machined by Sinking...

Fig. 4: a) Coefficient of friction for both materials and all four surface conditions; b) Time until vibration noise started and trial was discontinued for both materials and all four surface conditions.

The average white layer thickness of both materials after all three ED-machining sequences are depicted in Figure 5 a) [10]. The differences between the two materials can be explained according to the explanation of the different surface roughness above. The material CTF30 contains a lot more cobalt which already melts at lower temperatures and therefore the craters, but also the elevations at the rim of the crater become larger. The reverse of this effect for the super-finished specimens can be explained similarly. The white layer of UMG01 consists mostly of tungsten carbide and is therefore more difficult to remove [6].
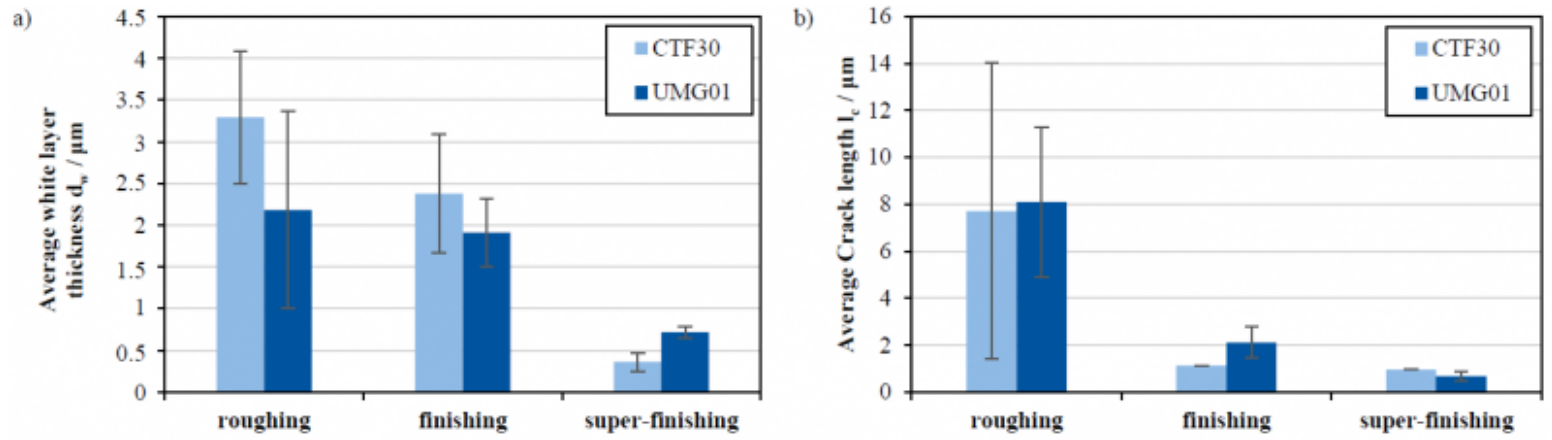

Fig. 5: a) Average white layer thickness [10] and b) average crack length of both materials after different EDmachining sequences.

The crack length, given in Figure $5 \mathrm{~b}$ ), was measured only within the base material and heat affected zone perpendicularly to the surface. The roughed surfaces showed some relatively large cracks in both materials. For the finished parts, the crack length has decreased significantly for both materials. For CTF30 however, the additional machining step does not reduce the crack length any further. Only for UMG01, the crack length can be reduced further with the super-finishing process.

The traverse rupture strength (TRS) for both materials and all three eroded surface conditions is shown in Figure 6 a). It becomes apparent that the machining strategy has a clear impact on the maximum stress the specimens could bear before they broke. The enhanced surface conditions after finishing and super-finishing can increase the TRS by $150 \%$. It can also be seen that the finely grained UMG01 can only withstand lower maximum stresses than the coarser CTF30. This is mostly caused by the different binder contents of the two materials and the slightly different properties of the surfaces cannot be hold responsible for this signi ficant deviation. However, even after super-finishing, the TRS of both materials lacks behind the values given by the manufacturer Ceratizit. CTF30 stays $20 \%$ behind the given value and UMG01 almost 50\%. It has to be noted that even after super-finishing, the influence of EDM cannot be neglected.

Figure 6 b) displays the hardness of both materials and all surface conditions. It is revealed that the influence of EDM on CTF30 is negligibly small. However, the excessively harder UMG01 displays great losses caused by EDM, while the influence is diminished through the finishing and super-finishing operations. The lower hardness of the ED-machined UMG01 can be attributed to the white layer, which is a lot larger than the grain size and thus the grain boundary strengthening effect is reduced. Fang [18] described a dependency between TRS and hardness. However, the TRS values described by him were not reached in this investigation and the tendency for CTF30 is reversed. For UMG01 the hardness is above those investigated by Fang and the TRS is below as well. 

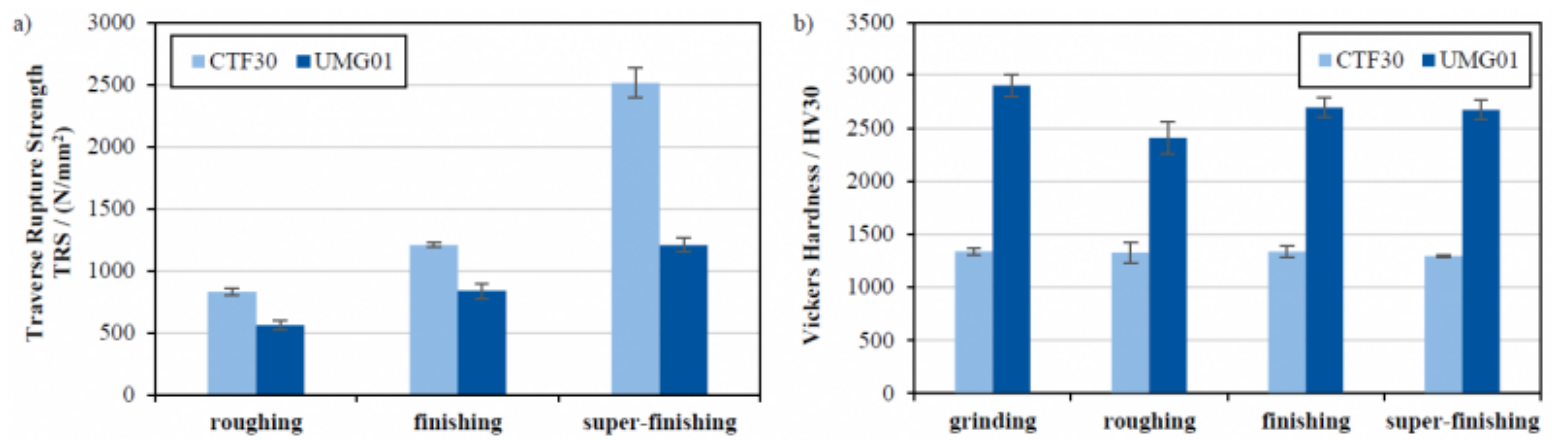

Fig. 6: a) Traverse rupture strength of both materials and all three surface conditions; b) Vickers hardness of both materials and all three surface conditions.

The crack surfaces that result from the 3-point bending test are presented in Figure 7. There the surfaces of CTF30 and UMG01 are compared for the roughed and the super-finished specimens. The roughed CTF30 specimen shows a very flat crack surface without any distinct changes. However, the crack surface of the super-finished specimen has a few ratchet marks and appears very rough. Once the crack is initiated, it will propagate through the material along the least energy-consuming path. Since the processing zone at the tip of the crack is relatively little for the roughed specimen, the crack can only continue perpendicular to the largest stress. Because the crack initiating flaws caused by the superfinishing process are a lot smaller than those introduced by roughing, they can be halted by work-hardening. However, at some load, the final crack is initiated and propagates with a comparably large processing zone, which allows the crack to take more distant options to propagate with fewer energy $[19,20]$.
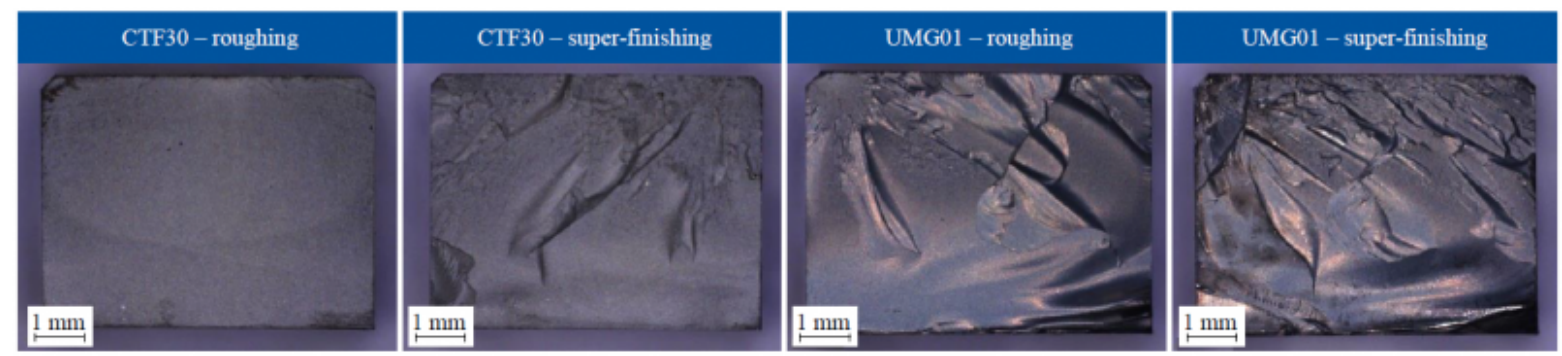

Fig. 7: Crack surfaces after the 3-point bending test of both materials and after different EDM sequences.

The crack surfaces of all UMG01 specimens show more ridges and ratchet marks than any of the CTF30 specimens. Because there is almost no binder in UMG01 and the crack propagation along and within WC-grains consumes less energy than that within the binder or along the boundary between binder and carbide grain, there is little resistance in the material to prevent the crack [19]. Both UMG01 surfaces look glossy in comparison with the prior described CTF30 surfaces, which is caused by the intergranular cracks between the tungsten carbide grains which reveal the grain surfaces of the tungsten carbide grains [20].

\section{Conclusion}

In this study, mechanical and tribological parameters of two cemented carbides grades machined by different electrical discharge machining strategies were investigated. Additionally, the results were compared with their own reference 
trials, information given by the manufacturer and literature. It was tried to identify dependencies between the properties that describe the surface integrity of the tested specimens with their mechanical and tribological properties. However, it was not possible to find dependencies between the coefficient of friction and the average surface roughness. Nevertheless, the results were in good accordance with some of the considered literature. The white layer and average crack length of both materials corresponded very well with the reduced discharge energies of subsequent machining steps. The white layer was mostly reduced through super finishing while the crack length declined already after finishing and only slight improvements were made through super finishing. The strong impact these surface conditions have at the mechanical properties was expressed with the results of the 3-point bending tests. The traverse rupture strength shows a strong dependency from the machining strategy. However, even with the best machining strategy is was not possible to meet the TRS values given by the manufacturer of the cemented carbides. Especially the ultrafine grained and almost binder free material UMG01 only reaches half the TRS value given by Ceratizit. The smaller resistance to crack propagation of UMG01 could be seen in the portrayed crack surfaces as well.

\section{Acknowledgments}

The authors thank the German Research Foundation (DFG) for funding the DFG project KL 500/153-1 "Analysis of discharge-dependent surface integrity of cemented carbide forming dies and its influence on the tribological characteristics and the resulting fatigue behavior".

\section{Bibliography}

[1] Klocke, F. Manufacturing processes: Forming. Springer, Berlin, New York, 2013. ISBN: 978-3-642-36772-4.

[2] Engel, U., Groenback J., Hinsel, C. Tooling solutions for challenges in cold forging. Umformtechnik, 2011.

[3] Cao, J., Brinksmeier, E., Fu, M., Gao, R.X. et al. Manufacturing of advanced smart tooling for metal forming. CIRP Annals, 2019, 68, p. 605-628, DOI: 10.1016/j.cirp.2019.05.001.

[4] Baer, O., Feuerhack, A., Voigts, H., Bergs, T. Investigation of the Mechanical Punch Loads during Fine Blanking of High-Strength Steels with Cemented Carbide. Procedia Manufacturing, 2019, 34, p. 90-100, DOI: 10.1016/ j.promfg.2019.06.125.

[5] Klink, A., Arntz, K., Johannsen, L., Holsten, M. et al. Technology-based assessment of subtractive machining processes for mold manufacture. Procedia CIRP, 2018, 71, p. 401-406, DOI: 10.1016/j.procir.2018.05.052.

[6] König, W., Wertheim, R., Weiß, A. Funkenerosive Bearbeitung von Hartmetall: Forschungsberichte des Landes Nordrhein-Westfalen. Westdeutscher Verlag GmbH, Opladen, 1974. ISBN: 978-3-531-02406-6.

[7] Casas, B., Torres, Y., Llanes, L. Fracture and fatigue behavior of electrical-discharge machined cemented carbides. International Journal of Refractory Metals and Hard Materials, 2006, 24, p. 162-167, DOI: 10.1016/ j.ijrmhm.2005.04.007.

[8] Andreas, K., Merklein, M., Engel, U. Influence of Combined Hard and Fine Machining on the Surface Properties of Cemented Carbides. Tribology in Industry, 2012, 34, p. 119-127.

[9] Juhr, H., Schulze, H.-P., Wollenberg, G., Künanz, K. Improved cemented carbide properties after wire-EDM by pulse shaping. Journal of Materials Processing Technology, 2004, 149, p. 178-183, DOI: 10.1016/j.jmatprotec.2004.02.037.

[10] Bergs, T., Petersen, T., Tombul, U., Klink, A. Analysis of the Influence of Surface Integrity of Cemented Carbides Machined by Sinking EDM on Flexural Fatigue. Procedia CIRP, 2020, 87, p. 456-461, DOI: 10.1016/j.procir.2020.02.096. 
[11] Mattfeld, P.-M. Tribologie der zinkphosphatfreien Kaltmassivumformung. Dissertation, RWTH Aachen University, Aachen, 2014. ISBN: 978-3-86359-195-3.

[12] DIN Deutsches Institut für Normung e.V. Hartmetalle - Bestimmung der Biegebruchfestigkeit, Berlin. Beuth Verlag GmbH, 77.040.10; 77.160, 2009(3327).

[13] Steuer, P. Gepulste elektrochemische Bearbeitung von Kupferelektroden und deren Einsatz zur funkenerosiven Strukturierung von Hartmetall: Dissertation, Saarbrücken, University of Saarland, 2015.

[14] Kolaska, H. Pulvermetallurgie der Hartmetalle, Hagen, Essen, 1992.

[15] Llanes, L. Influence of electrical discharge machining on the sliding contact response of cemented carbides. International Journal of Refractory Metals and Hard Materials, 2001, 19, p. 35-40, DOI: 10.1016/ S0263-4368(00)00045-7.

[16] Zhao, W., He, N., Li, L. Friction and Wear Properties of WC-Co Cemented Carbide Sliding against Ti6Al4V Alloy in Nitrogen Gas. Advanced Materials Research, 2011, 188, p. 49-54, DOI: 10.4028/www.scientific.net/AMR.188.49.

[17] Fang, S., Klein, S., Hsu, C.-J., Llanes, L. et al. Fabrication and tribological performance of a laser-textured hardmetal guiding stone for honing processes. International Journal of Refractory Metals and Hard Materials, 2019, 84, p. 105034, DOI: 10.1016/j.ijrmhm.2019.105034.

[18] Fang, Z.Z. Correlation of transverse rupture strength of WC-Co with hardness. International Journal of Refractory Metals and Hard Materials, 2005, 23, p. 119-127, DOI: 10.1016/j.ijrmhm.2004.11.005.

[19] Sigl, L.S., Fischmeister, H.F. On the fracture toughness of cemented carbides. Acta Metallurgica, 1988, 36, p. 887897, DOI: 10.1016/0001-6160(88)90143-5.

[20] González-Velázquez, J.L. Fractography and Failure Analysis. Springer International Publishing, Cham, 2018.

PDF automatically generated on 2021-05-22 01:21:16

Article url: https://popups.uliege.be/esaform21/index.php?id=1518

published by ULiège Library in Open Access under the terms and conditions of the CC-BY License (https://creativecommons.org/licenses/by/4.0) 